\title{
Surgery Nurses' Awareness on SBAR Communication Model and SBAR Training
}

\author{
Merve Vatan 1 , Tulin Yildiz \\ Tekirdağ Namık Kemal University, School of Health, Department of Nursing, Tekirdag, Turkey. \\ Correspondence Author: Tulin Yildiz \\ E-mail: tyildiz70@hotmail.com \\ Received: $01.09 .2020 \quad$ Accepted: 25.09.2021
}

\begin{abstract}
Objective: The study has been carried out to analyze surgery nurses' awareness on SBAR communication model and to measure the effectiveness of SBAR training on it. SBAR communication model, which abbreviates "situation, background, assessment and recommendation", undertakes a significant role to provide patient safety.

Methods: It was undertaken between 1 March 2019 - 30 April 2019 with a sample consisting of 138 nurses serving in surgical units of the hospital involved in the study. A session of 45-minute training, which has been delivered to surgery nurses, consisted of example scenarios and practices based on SBAR communication model as well as the user guide and some video shots related to communication settings in compliance with SBAR Model. The data were collected during pre-training, immediately after post-training and one-month after the posttraining sessions via face-to face interviews conducted with surgery nurses.

Results: Mean values of nurses' SBAR communication model awareness have been calculated for all 18 questions in the form. Those mean values have been displayed as $62.76 \pm 28.52$ during pre-training, $95.05 \pm 7.56$ during immediate post-training and $90.90 \pm 13.89$ during a-monthlater session of post-training. Comparisons of pre-training and post-training scores have displayed a statistically significant increase in mean values, both after the training and one month later $(p<0.05)$.

Conclusion: The findings observed in the study show that trainings have a positive effect on raising awareness with respect to SBAR communication model to measure the effectiveness of SBAR training on it.
\end{abstract}

Keywords: Patient Safety, Health Communication, Patient Care Planning, Nursing

\section{INTRODUCTION}

Communication is a core element of healthcare services and has a significant impact both on patient safety and clinical results. Healthcare organizations focus on promoting effective communication to prevent negative situations possible to result from communication failures (1). Patient safety is crucial for the delivery of effective, high-quality healthcare and is defined by the World Alliance for Patient Safety of World Health Organization (WHO) as follows: "The reduction of risk of unnecessary harm associated with healthcare to an acceptable minimum" (2). WHO states that every year, circa 10 million people encounter problems originated from avoidable medical practices, that's why WHO recommends making more research on patient safety (3). The objective of the concept is to maintain safety for patients, patient relatives and healthcare professionals by excluding potential factors that may physically and psychologically affect the healthcare environment in a negative manner (4). Regarding the report published by the Institute of Medicine in 1999, Joint Commission on Accreditation of Healthcare Organizations (JCAHO) has initiated implementations of patient safety all over the world, which have been collaborated by the Joint Commission International $(\mathrm{JCl})$. Being one of International Patient Safety Goals, which was announced by $\mathrm{JCl}$ in 2006 and updated in 2014, improvement of effective communication becomes a key factor for sustainable patient care and ensures safe care practices $(5,6)$. Effective communication failures in healthcare result in unexpected and critical outcomes for patients; retarded patient care, surgical mistakes, falling off, extended hospitalization, serious injuries and even death are some examples of those critical outcomes (7). Among effective communication 
techniques, the most widely used one, which covers a place of $69.6 \%$, is SBAR (Situation-Background-AssessmentRecommendation) Communication Model (8). It is an evidence-based professional communication model which creates a framework for how to convey patient-related information through short-cut, clear, quick and explicit ways to other health professionals, especially in emergency situations $(9,10)$. Communication among healthcare professionals is required for high-quality care and patient safety particularly when critical cases occur. Nevertheless, SBAR awareness and utilization of this communication model in clinical units are considered to realize less commonly. In that context, this research, which has been planned as a descriptive study, aims to analyze SBAR communication model awareness of surgery nurses before and after SBAR training, considering pre-training, immediate post-training and the first subsequent month results.

\section{METHOD}

\subsection{Research Design and Sample}

The research has been carried out as a descriptive study to identify SBAR communication model awareness of nurses who work at surgery units of a university hospital. The study universe comprised 220 surgery nurses working at the surgery service, surgical ambulatory care and surgery room of the hospital during $1^{\text {st }}$ March $2019-30^{\text {th }}$ April 2019. The sampling has consisted of 138 surgery nurses who were selected by simple random sampling method and who were up to research criteria and confirmed their participation in the survey.

\subsection{Data Collection}

The research data have been acquired through face-to-face interviews of the researcher. As a starting step, "Personal Info Sheet" and "SBAR Communication Model Assessment Form" have been completed by participants as a pre-test, prior to the training. The 45-minute training session has been initiated by a Power Point slideshow delivering information to surgery nurses about SBAR communication model. In video shots on communication practices, the use of SBAR communication model has been explained through example scenarios. In order to guide further, SBAR Communication Model brochure has been delivered to nurses before they leave the training room. Post-test was applied to participants, again during face-to-face interviews, just after the training and one month later.

"Personal Info Sheet" and "SBAR Communication Model Assessment Form" have been utilized for data collection. Both tools have been prepared by researchers after consulting the field experts and referring to the literature (11-13).

Personal Info Sheet consists of 5 questions concerning personal features of nurses (age, gender, education, department where they are employed and duration of their employment).

SBAR Communication Model Assessment Form consists of questions determining surgery nurses' awareness on SBAR communication model and previous training experience about the concept. In addition, the frequency of their use of SBAR model and its effectiveness has also been checked through questions. In the form, there are 18 True-False questions to assess surgery nurses' SBAR communication model awareness levels. The scale varies from 0 to 1 as the former representing false and the latter representing true responses. Thus, the minimum score becomes 0 and maximum score reaches to 18 . The calculation results have been standardized by converting them to 100 point scaling. Kuder-Richardson-21 test has been used to measure the internal consistency value of SBAR Communication Model Assessment Form through its 18 true-false statements. Considering validity results, the form has been found to be highly valid and reliable (Table 1 ).

Table 1. SBAR Communication Model Assessment Form Validity and Reliability

\begin{tabular}{cc}
\hline $\begin{array}{c}\text { SBAR Communication Model } \\
\text { Assessment Form }\end{array}$ & Kuder-Richardson-21 Info Model \\
\hline Pre-Training (18 questions) & 0.896 \\
\hline $\begin{array}{c}\text { Post-Training (Immediate) } \\
\text { (18 questions) }\end{array}$ & 0.791 \\
\hline $\begin{array}{c}\text { Post-Training (1 } 1^{\text {st }} \text { Month) } \\
\text { (18 questions) }\end{array}$ & 0.821 \\
\hline
\end{tabular}

\section{Research question}

How high is SBAR communication model awareness of nurses?

How high is the impact of SBAR training on surgery nurses?

\subsection{Ethical Consent}

In order to carry out the research, written consent of the Non-initiative Clinical Research Ethical Committee (No: 2019.23.02.07), which is affiliated to the Faculty of Medicine, has been taken as well as the written permission of Health Practices and Research Centre, where the study would be implemented. Surgery nurses who would take part in the survey have been informed about the research procedures before getting their oral and written consent. Regarding the privacy policy, the identities of participants have not been disclosed in the article.

\subsection{Statistical Analysis}

The institutional statistics program has been utilized to process the data. Descriptive statistical methods such as mean, standard deviation, median, frequency, percent, 
minimum and maximum scores have all been performed during analyses. Shapiro-Wilk test and graphical tools have been used to measure the normality of the population. In addition, Mann-Whitney $U$ test has been used to compare two groups of not normally distributed variables and Kruskall Walls test has been conducted to compare three or more groups derived from not normally distributed variables. Pair-wise adjustments have been done through BonferroniDunn post hoc test. The validity and reliability of 18 items in Nurses' SBAR Communication Model Assessment Form has been tested by Kuder Richardson-21, whereas Friedman test measured the effects of not normally distributed variables. Bonferroni-Dunn test has been again performed to reach pair-wise comparisons of those variables. For the interpretations of analyses, $\mathrm{p}<0.05$ has been accepted as the level of statistical significance.

\section{RESULTS}

The study has been conducted with 138 surgery nurses in total; $86.2 \%(n=119)$ of whom have been females and $13.8 \%(n=19)$ has been composed of males. The age average of participants has been $29.52 \pm 5.75$ years. $71.8 \%$ of participants were graduates with Bachelor's degree. Among the participants, $71 \%$ has been employed in surgery service units whereas $37.7 \%$ of them having professional background of $1-5$ years.

Table 2. Distribution of Knowledge and Training Background about SBAR Communication Model

\begin{tabular}{llccccccc} 
& & & \multicolumn{3}{c}{ Pre-Training } & $\begin{array}{c}\text { Post-Training } \\
\text { Immediate }\end{array}$ & \multicolumn{2}{c}{$\begin{array}{c}\text { Post-Training } \\
\mathbf{1}^{\text {st. }} \text {. Month }\end{array}$} \\
\cline { 3 - 9 } & & $\mathbf{n}$ & $\%$ & $\mathbf{n}$ & $\%$ & $\mathbf{n}$ & $\%$ \\
\hline $\begin{array}{l}\text { Knowledge } \\
\text { about SBAR }\end{array}$ & Yes & 28 & 20,3 & 138 & 100 & 138 & 100 \\
\cline { 2 - 9 } & No & 110 & 79,7 & - & - & - & - \\
\hline $\begin{array}{l}\text { Training } \\
\text { Background } \\
\text { about SBAR }\end{array}$ & Yes & No & 15 & 10,9 & 138 & 100 & 138 & 100 \\
\hline $\begin{array}{l}\text { Training } \\
\text { Setting }\end{array}$ & Formal & 2 & 13,3 & 2 & 1,4 & 2 & 1,4 \\
\hline & In-service & 13 & 86,7 & 136 & 98,6 & 136 & 98,6 \\
\hline
\end{tabular}

According to pre-training results, participants' knowledge about SBAR communication model and their eagerness to use the model seems at very low percentages though the rates keep inclining just after the training and one month later (Table 2).

The responses by nurses to the questions "Do you think SBAR communication model is effective on patient safety?" and "Would you like to practice SBAR communication model in your professional life?" display low rates for pre-training stage. However, the rates referring to its effectiveness and nurses' willingness to practice in clinic settings show an increase both at immediate post-training and at the-firstmonth stages (Table 3).

Table 3. Distribution of the Effectiveness of SBAR on Patient Safety and Willingness to Use in Professional Settings

\begin{tabular}{|c|c|c|c|c|c|c|}
\hline & \multicolumn{2}{|c|}{ Pre-training } & \multicolumn{2}{|c|}{$\begin{array}{l}\text { Post-training } \\
\text { (Immediate) }\end{array}$} & \multicolumn{2}{|c|}{$\begin{array}{l}\text { Post-training } \\
\text { (1st month) }\end{array}$} \\
\hline & $\mathrm{n}$ & $\%$ & $\mathbf{n}$ & $\%$ & n & $\%$ \\
\hline \multicolumn{7}{|c|}{ Do you think SBAR communication model is effective on patient safety? } \\
\hline Never effective & 6 & 4,3 & 1 & 0,7 & 1 & 0,7 \\
\hline Not really effective & 3 & 2,2 & 1 & 0,7 & 0 & 0 \\
\hline Partially effective & 33 & 23,9 & 4 & 2,9 & 12 & 8,7 \\
\hline Effective & 43 & 31,2 & 20 & 14,5 & 28 & 20,3 \\
\hline Very effective & 53 & 38,4 & 112 & 81,2 & 97 & 70,3 \\
\hline
\end{tabular}

Would you like to practice SBAR communication model in your professional life?

\begin{tabular}{l|cccccc} 
I never use it & 41 & 29,7 & 11 & 8,0 & 3 & 2,2 \\
\hline I don't use it & 16 & 11,6 & 10 & 7,2 & 2 & 1,4 \\
\hline I sometimes use it & 53 & 38,4 & 23 & 16,7 & 30 & 21,7 \\
\hline I use it & 17 & 12,3 & 26 & 18,8 & 35 & 25,4 \\
\hline I always use it & 11 & 8 & 68 & 49,3 & 68 & 49,3 \\
\hline
\end{tabular}

Regarding the distribution of pre-training responses to questions measuring SBAR awareness among nurses, the lowest accuracy score goes to the statement "I believe that SBAR communication model urges me to questioning after a stressful situation" whereas the highest accuracy score goes to "I believe communication problems in patient care may lead to serious medical errors". Compared to those pretraining results, all the accurate responses given by nurses tend to increase just after the training and one month later (Table 4). 
Table 4. Distribution of SBAR Communication Model Awareness Levels

\begin{tabular}{|c|c|c|c|c|c|c|}
\hline \multirow[t]{2}{*}{ SBAR Communication Model } & \multicolumn{2}{|c|}{ Pre-Training } & \multicolumn{2}{|c|}{$\begin{array}{l}\text { Post-Training } \\
\text { (Immediate) }\end{array}$} & \multicolumn{2}{|c|}{$\begin{array}{l}\text { Post-Training } \\
\text { (1st month) }\end{array}$} \\
\hline & $\begin{array}{l}\text { True } \\
\mathrm{n} \%\end{array}$ & $\begin{array}{c}\text { False } \\
\mathrm{n} \%\end{array}$ & $\begin{array}{l}\text { True } \\
\mathrm{n} \%\end{array}$ & $\begin{array}{c}\text { False } \\
\mathrm{n} \%\end{array}$ & $\begin{array}{l}\text { True } \\
\mathrm{n} \%\end{array}$ & $\begin{array}{c}\text { False } \\
\mathrm{n} \%\end{array}$ \\
\hline $\begin{array}{l}\text { 1.I believe that communication problems in patient care may lead to serious } \\
\text { medical errors. }\end{array}$ & $109(79)$ & $29(21)$ & $134(97.1)$ & $4(2.9)$ & $127(92)$ & $11(8)$ \\
\hline 2.SBAR enhances communication with physician in the clinic. & $85(61.6)$ & $53(38.4)$ & $129(93.5)$ & $9(6.5)$ & $124(89.9)$ & $14(10.1)$ \\
\hline $\begin{array}{l}\text { 3.SBAR is not a reliable and approved communication tool that reduces adverse } \\
\text { cases. }\end{array}$ & $80(58)$ & $58(42)$ & $132(95.7)$ & $6(4.3)$ & $122(88.4)$ & $16(11.6)$ \\
\hline $\begin{array}{l}\text { 4.SBAR is a professional communication technique that facilitates short-cut, clear, } \\
\text { thorough and standardized communication among healthcare professionals in } \\
\text { order to achieve prevalent exchange of information. }\end{array}$ & $97(70.3)$ & $41(29.7)$ & $134(97.1)$ & $4(2.9)$ & $135(97.8)$ & $3(2.2)$ \\
\hline $\begin{array}{l}\text { 5.SBAR communication model denotes the abbreviation of 'Situation, Background, } \\
\text { Assessment, Recommendation'. }\end{array}$ & $95(68.8)$ & $43(31.2)$ & $138(100)$ & $0(0)$ & $134(97.1)$ & $4(2.9)$ \\
\hline $\begin{array}{l}\text { 6. When referring to part "S" of SBAR communication model, the question "What } \\
\text { is the current situation of the patient?"is responded. }\end{array}$ & $90(65.2)$ & $48(34.8)$ & $137(99.3)$ & $1(0.7)$ & $136(98.6)$ & $2(1.4)$ \\
\hline $\begin{array}{l}\text { 7.When referring to part "B" of SBAR communication model, the question "Why } \\
\text { does the patient come? / What is his/her clinical background?"is responded. }\end{array}$ & $92(66.7)$ & $46(33.3)$ & 134(97.1) & $4(2.9)$ & $132(95.7)$ & $6(4.3)$ \\
\hline $\begin{array}{l}\text { 8. When referring to part "A" of SBAR communication model, the question "In my } \\
\text { opinion, what is the problem?" is responded. }\end{array}$ & $80(58)$ & $58(42)$ & $135(97.8)$ & $3(2.2)$ & $127(92)$ & $11(8)$ \\
\hline $\begin{array}{l}\text { 9. When referring to part " } R \text { " of SBAR communication model the question "What is } \\
\text { my recommendation?" is responded. }\end{array}$ & $92(66.7)$ & $46(33.3)$ & $135(97.8)$ & $3(2.2)$ & $135(97.8)$ & $3(2.2)$ \\
\hline 10.SBAR creates a lingua franca (common language) for healthcare professionals. & $103(74.6)$ & $35(25.2)$ & $133(96.4)$ & $5(3.6)$ & $115(83.3)$ & 23(16.7) \\
\hline $\begin{array}{l}\text { 11.SBAR Communication Model is not helpful for easy recognition and encouraging } \\
\text { prioritized preparations for communication. }\end{array}$ & $76(55.1)$ & $62(44.9)$ & $123(89.1)$ & $15(10.9)$ & $96(69.9)$ & $42(30.4)$ \\
\hline 12.In the Recommendation section, an advice can be given to the physician. & $58(42)$ & $80(58)$ & $120(87)$ & $18(13)$ & $129(93.5)$ & $9(6.5)$ \\
\hline 13.SBAR improves communication, increases patient safety. & $103(74.6)$ & $35(25.4)$ & $136(98.6)$ & $2(1.4)$ & 134(97.1) & $4(2.9)$ \\
\hline $\begin{array}{l}\text { 14.SBAR Communication Model is a structured communication tool that displays } \\
\text { reduction of negative cases in hospital settings. }\end{array}$ & $88(63.8)$ & $50(36.2)$ & $136(98.6)$ & $2(1.4)$ & $127(92)$ & $11(8)$ \\
\hline $\begin{array}{l}\text { 15. The rationale of a patient's problem should be dwelled on during the Situation } \\
\text { section. }\end{array}$ & $80(58)$ & $58(42)$ & $129(93.5)$ & $9(6.5)$ & $127(92)$ & $11(8)$ \\
\hline 16.SBAR can be used in all occasions where patient's data is conveyed. & $81(58.7)$ & $57(41.3)$ & $126(91.3)$ & $12(8.7)$ & $128(92.8)$ & $10(7.2)$ \\
\hline $\begin{array}{l}\text { 17.I believe that bedside delivery via SBAR Communication Model helps patient } \\
\text { care. }\end{array}$ & $97(70.3)$ & $41(29.7)$ & $135(97.8)$ & $3(2.2)$ & $123(89.1)$ & $15(10.9)$ \\
\hline $\begin{array}{l}\text { 18.I believe that SBAR communication model urges me to questioning after a } \\
\text { stressful situation }\end{array}$ & $53(38.4)$ & $85(61.6)$ & $115(83.3)$ & $23(16.7)$ & $107(77.5)$ & $31(22.5)$ \\
\hline
\end{tabular}

Nurses' pre-training awareness scores for SBAR communication model vary on a scale between 0 and 100 . However, both post-training scores and the ones received in the first month are found to be higher than the pre-training results $(p<0.01)$ (Table 5$)$.
Considering the distribution of SBAR awareness scores in units, a statistically significant difference emerges from the comparison of post-training and pre-training scores of various groups $(p<0.05)$. The results exhibit higher difference for nurses working in the operation room than their counterparts working in the ambulatory care unit $(p=0.049 ; p<0.05)$ (Table 6).

Table 5. Assessment of SBAR Communication Model Awareness Scores

\begin{tabular}{|c|c|c|}
\hline & \multicolumn{2}{|c|}{ SBAR Communication Model Awareness Scores } \\
\hline & Min.-Max. (Median) & Mean \pm Std. Dv. \\
\hline Pre-Training & $0-100(66,7)$ & $62,76 \pm 28,52$ \\
\hline Post-Training (Immediate) & $66,7-100(100)$ & $95,05 \pm 7,56$ \\
\hline Post-Training (1st. Month) & $11,1-100(94,4)$ & $90,90 \pm 13,89$ \\
\hline Test value & \multicolumn{2}{|c|}{ 国:145,591 } \\
\hline${ }^{\mathrm{a}} \boldsymbol{p}$ & \multicolumn{2}{|c|}{$0,001 * *$} \\
\hline Difference (Pre-T. - Post-T. Im.) & $-16,7 / 100(27,8)$ & $32,29 \pm 29,07$ \\
\hline Difference (Post-T. 1st M. - Pre-T.) & $-44,5 / 100(22,2)$ & $28,14 \pm 30,32$ \\
\hline Difference (Post-T. 1st M. - Post-T. Im.) & $-83,3 / 22,2(0)$ & $-4,15 \pm 14,60$ \\
\hline
\end{tabular}


Table 6. Assessment of SBAR Communication Model Awareness Scores Regarding the Unit of Employment

\begin{tabular}{|c|c|c|c|c|c|}
\hline & & \multicolumn{3}{|c|}{ Unit of Employment } & \multirow{2}{*}{$\begin{array}{c}\text { Test value } \\
{ }^{\mathrm{b}} \boldsymbol{p}\end{array}$} \\
\hline & & Surgery Service $(n=98)$ & $\begin{array}{l}\text { Ambulatory Care } \\
(n=24)\end{array}$ & Operation Room ( $n=16)$ & \\
\hline \multirow[t]{2}{*}{ Pre-Training } & Min.-Max. (Median) & $0-100(66,7)$ & $27,8-100(75)$ & $0-100(50)$ & \multirow{2}{*}{$\begin{array}{c}]^{2}: 2,445 \\
0,294\end{array}$} \\
\hline & Mean \pm Std. Dv. & $61,91 \pm 28,48$ & $71,99 \pm 19,90$ & $54,17 \pm 36,82$ & \\
\hline \multirow[t]{2}{*}{ Post-Training (Immediate) } & Min.-Max. (Median) & $66,7-100(100)$ & $72,2-100(94,4)$ & $88,9-100(100)$ & \multirow{2}{*}{$\begin{array}{c}0^{2}: 13,165 \\
0,001 * *\end{array}$} \\
\hline & Mean \pm Std. Dv. & $95,29 \pm 7,28$ & $91,20 \pm 9,11$ & $99,31 \pm 2,78$ & \\
\hline \multirow[t]{4}{*}{ Post-Training(1 ${ }^{\text {st }}$. Month) } & Min.-Max. (Median) & $11,1-100(94,4)$ & $61,1-100(94,4)$ & $77,8-100(94,4)$ & \multirow{2}{*}{$\begin{array}{c}?^{2}: 0,286 \\
0,867\end{array}$} \\
\hline & Mean \pm Std. Dv. & $90,48 \pm 15,28$ & $90,74 \pm 11,31$ & $93,75 \pm 6,69$ & \\
\hline & Test value & $?^{2}: 109,009$ & [? $2: 20,076$ & ]$^{2}: 17,760$ & \\
\hline & ${ }^{\mathrm{a}} p$ & $0,001^{* *}$ & $0,001 * *$ & $0,001^{* *}$ & \\
\hline \multirow{2}{*}{$\begin{array}{l}\text { Difference } \\
\text { (Pre-T. / Post-T. Im.) }\end{array}$} & Min.-Max. (Median) & $-16,7 / 100(27,8)$ & $0 / 61,1(13,9)$ & $0 / 100(50)$ & \multirow{2}{*}{$\begin{array}{c}?^{2}: 6,678 \\
0,035^{*}\end{array}$} \\
\hline & Mean \pm Std. Dv. & $33,39 \pm 28,51$ & $19,21 \pm 19,59$ & $45,14 \pm 37,62$ & \\
\hline \multirow{2}{*}{$\begin{array}{l}\text { Difference (Post-T. } 1^{\text {st }} . \text { M. / } \\
\text { Pre-T.) }\end{array}$} & Min.-Max. (Median) & $-44,5 / 100(22,2)$ & $-11,1 / 61,1(8,3)$ & $-11,1 / 88,9(44)$ & \multirow{2}{*}{$\begin{array}{c}?^{2}: 3,395 \\
0,183\end{array}$} \\
\hline & Mean \pm Std. Dv. & $28,57 \pm 30,48$ & $18,75 \pm 23,04$ & $39,58 \pm 35,94$ & \\
\hline \multirow{2}{*}{$\begin{array}{l}\text { Difference (Post-T. } 1^{\text {st }} . \text { M. / } \\
\text { Post-T. Im.) }\end{array}$} & Min.-Max. (Median) & $-83,3 / 22,2(0)$ & $-22,2 / 22,2(0)$ & $-22,2 / 5,6(-5,6)$ & \multirow{2}{*}{$\begin{array}{c}?^{2}: 2,491 \\
0,288\end{array}$} \\
\hline & Mean \pm Std. Dv. & $-4,82 \pm 16,34$ & $-0,46 \pm 9,54$ & $-5,56 \pm 7,31$ & \\
\hline${ }^{\mathrm{a}}$ Friedman Test & ${ }^{\mathrm{b}}$ Kruskal Wallis Test & ${ }^{*} p<0,05$ & $* * p<0,01$ & & \\
\hline
\end{tabular}

\section{DISCUSSION}

Current nursing care focuses on therapeutic communication with patients and general human communication aspect (14). Surgery services, ambulatory care units and operation rooms are departments where emergency responses and initiatives frequently occur, critical check-outs and quick decision making emerges and communication-based teamwork is required $(15,16)$. Our research has been conducted with nurses employed at surgical service units, ambulatory care units and operation rooms. Pre-training results have shown that participants' knowledge of SBAR communication model was at low percents but the training has created awareness of nurses and this awareness has been triggered by training repetitions. Chetwood et al ${ }^{12}$ has stated that only $15 \%$ of the participants had some knowledge about SBAR communication model prior to their training (12). Practicing out inter-professional communication in an evidence-based manner is considered is vital for nursing and especially for patient safety. Contradicting to that importance, study results have revealed both the knowledge and the use of SBAR have been scarce before the training, just to verify the previous literature $(1,12,17)$. The low rate of surgical nurses' SBAR knowledge deficiency prior to training is considered to emerge from the limited coverage of SBAR modules in both formal education and in-service programmes. In our study, prior to the training, very few nurses have mentioned the effectiveness of SBAR and their willingness to use the model in the clinic whereas this number has increased after the training. An earlier study shows the improvement of team work, safety climate and job satisfaction among healthcare professionals via the use of SBAR model (17). Another research informs that after using SBAR, nurses have encountered fewer errors and felt higher self-confidence due to the facilitating power of the model on inter-professional communication (1). Raymond and Harrison's study, which is about the use of SBAR Communication Model in neonatology, reports SBAR use before the training at $29 \%$ though with a rising rate to $70 \%$ after the training (18). According to Achrekar et al. who analyze the impact of SBAR on nursing practices, $63 \%$ of nurses state that SBAR communication model will totally increase patient safety while $37 \%$ saying the increase will be partial (11). Bloom at al.'s research, which compares preintervention and post-intervention opinions of surgeons and surgery nurses, reveals that after the training, the majority of surgeons and nurses agree with the statement suggesting "SBAR communication model ensures patient safety by improving communication" (19). De Meester et al. figure out the effectiveness of SBAR on early diagnosis of the changes in patients' general situations and the planning of nursing care (1). The significance of SBAR communication model for patient safety is also emphasized by previous literature (1, 11, 17-19). Patient's information to be conveyed becomes standardized in a framework by SBAR communication model. Thus, SBAR model enhances team-wise work by avoiding the loss of relevant information and that ensures its vitality for patient safety. The study reveals the need for the recognition and practice of SBAR communication model by healthcare professionals.

\section{Limitation}

The study has been carried out with surgery nurses only in one centre. It has not been tested whether SBAR was being used by nurses before or not, only their statements have been analyzed through the form. Therefore, it is not possible to generalize the study results to all nurses and other departments. It is recommended to perform more researches with larger sampling groups to comment on the use of SBAR as well. 


\section{CONCLUSION}

SBAR training delivered to nurses has enhanced the perception of effective communication and cooperation by healthcare professionals. Compared to pre-training results, it has been detected that nurses' SBAR awareness after the training has increased and a rising trend has appeared about the use of the model in clinics. It is recommended to deliver trainings on communication models in formal education and its sustainability should be allowed via in-service training programmes.

\section{REFERENCES}

[1] De Meester K, Verspuy M, Monsieurs KG, Van Bogaert P. SBAR improves nurse-physician communication and reduces unexpected death: $A$ pre and post intervention study. Resuscitation 2013; 84: 1192-1196. doi: 10.1016/j. resuscitation.2013.03.016.

[2] Müller M, Jürgens J, Redaèlli M, Klingberg K, Stock S. Impact of the communication and patient hand-off tool SBAR on patient safety: A systematic review. BMJ Open 2018; 8e: 1-10.

[3] World Health Organization (WHO). Call for more research on patient safety. Available from: URL: http://www.who.int/ mediacentre/news/releases/2007/pr52/en/.

[4] Karaca A, Arslan H. A study to assess patient safety culture in nursing services. Journal of Health and Nursing Management 2014; 1(1): 9-18. (Turkish)

[5] Joint Commission International Accreditation Standards for Hospital. Joint commission resource, updated international patient safety goals text now, On JCI Web Site, 2014. Available from: URL: http://tr.jointcommissioninternational.org.

[6] Shahid S, Thomas S. Situation, Background, Assessment, Recommendation (SBAR) communication tool for handoff in health care-A narrative Review. Safety in Health 2018; 4(1): 1-9.

[7] Umberfield, E, Ghaferi AA., Krein IS, Manojlovich M. Using incident reports to assess communication failures and patient outcomes. Jt Comm J Qual Patient Saf 2019; 45(6): 406-413.

[8] Riesenberg L, Leitzsch L. Brian W. Systematic review of handoff mnemonics literature. Am J Med Qual 2009; 24(3): 196-204.
[9] Randmaa M, Mårtensson G, Swenne CL, Engström M. SBAR Improves communication and safety climate and decreases incident reports due to communication errors in an anaesthetic clinic: A prospective intervention study. BMJ Open. 2014; 4(1): 42-68.

[10] Başol E. Communication problems between patient and healthcare professionals (Physician and Nurse) and recommended solutions. IAAOJ 2018; 2(1): 76-93. (Turkish)

[11] Achrekar MS, Murthy V, Kanan S, Shetty R, Nair M, Khattry $\mathrm{N}$. Introduction of situation, background, assessment, recommendation into nursing practice: A prospective study. Asia Pac J Oncol Nurs 2016; 3(1): 45-50.

[12] Chetwood JD, Garg P, Burton K. High-fidelity realistic acute medical simulation and SBAR training at a Tertiary Hospital in Blantyre, Malawi. Simul Health 2018; 13(2): 139-145.

[13] Campbell D, Dontje K, Lansing E. Implementing bedside handoff in the emergency department: A Practice improvement project. J Emerg Nurs 2019; 45(2): 149-154.

[14] Jeong JH, Kim EJ. Development and evaluation of an SBARbased fall simulation program for nursing students. Asian Nursing Research 2020; 14:114-121.

[15] Özlü KZ, Eskici V, Aksoy D, Özer N, Yayla A, Avşar G. Determining the viewpoints and experiences of surgery clinic nurses about erroneous medication practices. Ankara Journal of Health Sciences 2015; (1-2-3): 83-103. (Turkish)

[16] Uğraş AG, Akyolcu N, Kanat C, Yüksel S, Ayoğlu T, Sayın Y, Kanan $\mathrm{N}$. Job safety for nurses serving at surgery clinics. Florence Nightingale Nursing Journal 2018; 26(2): 93-101. (Turkish)

[17] Wan-Hua T, Fu-Shiang P, Ho-Hsiung L, Sheng-Mou H. The impact of situation-background-assessment recommendation (SBAR) on safety attitudes in the obstetrics department, Taiwanese Journal of Obstetrics \& Gynecology 2017; 56: 171174.

[18] Raymond M, Harrison MC. The Structured Communication tool SBAR (Situation, Background, Assessment and Recommendation) improves communication in neonatology. SAMJ: South African Medical Journal 2014; 104 (12): 850-852.

[19] Blom L, Petersson P, Hagell P, Westergren A. The Situation, Background, Assessment and Recommendation (SBAR) Model for communication between health care professionals: A clinical intervention pilot study. International Journal of Caring Sciences 2015; 8(3):530-535. 